\title{
Universities Third Mission as a Drive for Academic Spin-Offs Creation and Regional Development. ASO Performance Indicators and External Influencing Factors: A Literature Review
}

\author{
De Turi Ivano \\ LUM Jean Monnet University \\ Italy
}

\begin{abstract}
In the last decade, there was a significant increase in the number of academic spin-offs in Europe based on a change in government incentives that foster universities and research institutions to share and commercialize their research results. Besides teaching and research, it is the third mission for universities and research institutions to support economic and social development by commercializing the output of basic research through technology transfer. In this paper there is a literature review on the field of academic spin-offs performance indicators and related influencing factors in order to identify which indicators and which external factor does the academic community consider most appropriate for this assessment
\end{abstract}

Keywords: entrepreneurial innovation, regional development, academic spin-offs, technology transfer, third mission, external environment

\section{Introduction}

The creation of academic spin-offs is normally concerned with bringing to the market the results of scientific research. Through this tool universities can have a role in creating opportunities for skilled employment and economic wealth tied to highly innovative activity. The opportunities related to that instrument are many, from the creation of a network or cluster of companies linked to the University (opportunities of collaborations and research contracts) to a useful contribution to the development of the territory. Then the university becomes a "knowledge factory, a factory specialized human capital, a factory dedicated to technology transfer, as well as a factory with the mission of territorial development, through the promotion and management of projects for territorial innovation (Lazzeroni \& Piccaluga, 2003). Many universities and research institutions have established technology transfer capabilities, i.e., resources to transfer technologies from the academic environment to industrial application, there is still a technology transfer gap between academia and industry, which has to be bridged for effective and efficient technology transfers in order to create industrial applications out of academic research and development $(R \& D)$ results. This gap can be addressed by spin-offs created from universities and research institutions, which translate the new knowledge into industrial applications, i.e., facilitating the transfer of R\&D results into products and services (Festel, 2015, a). Technological innovation includes the organization and direction of human capital resources towards effectively, (1) creating new knowledge which is mainly done at universities and research institutions, (2) generating technical ideas aimed at new and enhanced products, manufacturing processes and services as well as, (3) transferring them into manufacturing, distribution and use which is done by industrial companies (Roberts, 2007, a). Technology transfer, as the last steps, is crucial for the application of new technologies, especially within emerging sectors based on fast technological development (Festel, 2015, b). Faculties should engage in projects related to industry, because they improve their teaching and research experience and it promotes practical education for the students. In the same way, it is considered that the technology transfer's goal is the social well-being and that it also improves basic research (Quetglas and Grau, 2002). Conventional approaches to valuing the economic activity generated by colleges and universities often focus on direct employment or expenditure effects, along with a multiplier effect to capture indirect and induced outcomes. However, the potential influence of colleges and universities goes beyond these standard effects for an important reason: these institutions can help build the knowledge and skills - or human capital - of a region's people, a critical component of an area's economic success. Regional Development should be evaluated in terms of competitiveness that is the set of institutions, policies, and factors that determine the level of productivity of a country. A tool to measure the competitiveness of a region is the GCI. The Global Competitiveness Index is measured in accordance with the theory of countries' development stages (Porter et al, 2001). 
GCI consists of 12 pillars of competitiveness, which are grouped in 3 groups: (1) Basic requirements are the most important for countries that are in the stage of factor-driven growth. These factors are effective institutions, good infrastructure, a stable macroeconomic environment, quality of health and primary education. (2) Efficiency enhancers are the most important for countries that are in the stage of investment-driven growth (the second stage of development common in medium income countries. Their competitiveness depends on infrastructure, foreign direct investment and modern technologies). The factors are higher education and training, efficient goods and labor markets, developed financial markets, technological readiness and market size. (3) Innovation and sophistication are the most important for countries that are in the stage of innovation-driven growth (the third stage of development common in high-income countries. Their competitiveness depends on R\&D and a highly educated labor-force). These factors are business sophistication and innovation (Vaiva, 2016). A region with higher levels of human capital tends to have greater amounts of economic activity and more rapid economic growth. In addition, its workers tend to be more productive and earn higher wages (Abel, Deitz, 2012). In declining regions, academic institutions tend to bring stability to area economies. Colleges and universities can help build the knowledge and skills of a region's people. A region with higher levels of human capital has greater amounts of economic activity and more rapid economic growth, its workers being more productive and earning higher wages. The knowledge and new technologies created through research activities (Nicolăescu, 2013b) at colleges and universities can help local businesses grow. Higher levels of economic activity may be driving an increase in human capital levels if highly skilled people are attracted to productive places. Higher levels of human capital in a region (Pera, 2014a) can contribute to higher levels of economic activity increasing individual level productivity and the generation of ideas. Education increases the human capital inherent in the labor force, may increase the innovative capacity of the economy (Naito, 2013), and may facilitate the diffusion and transmission of knowledge needed to understand and process new information and to implement new technologies devised by others. Education is important as both an investment in human capital and in facilitating research and development and the diffusion of technologies (Nica, Popescu, 2014). Technological innovation includes the organization and direction of human capital resources towards effectively, (1) creating new knowledge which is mainly done at universities and research institutions, (2) generating technical ideas aimed at new and enhanced products, manufacturing processes and services as well as, (3) transferring them into manufacturing, distribution and use which is done by industrial companies (Roberts, 2007, b). Technology transfer represents a fundamental phase for the enforcement of new technologies, particularly within emerging sectors founded on fast technological development. Spin-offs make state-of-the-art technological expertise from academic research available for established companies, which can use these to leverage their product development and global sales capabilities. Technology transfer from academia to industry creates a win-win situation for all participants leading to a faster dissemination of academic knowledge into practice and resulting in an economic advantage (Festel, Rittershaus, 2014). In the last decade, the increase of the number of academic spin-offs in Europe is based on a change in government policies that encourage universities and research institutions to commercialize their research results. Besides teaching and research, it is the third mission for universities and research institutions to support economic and social development by commercializing the output of basic research through technology transfer (Etzkowitz et al. 2000; Etzkowitz 2003). The rise in number of academic spin-offs seems to be accelerated by at least three contextual factors. First, the ownership of intellectual property rights by technology transfer offices (TTOs) relative to that of faculty has increased. Most countries have enacted Bayh-Dole-like legislation, which grants universities the rights over their own intellectual property (OECD, 2003). As noted in Siegel et al. (2003), this is a first step towards the professionalization of the TTO. To support the management of intellectual property (IP) at universities, universities, regional and national governments and the European Commission have provided various types of financial support for TTOs. Second, there is increasing institutional pressure on universities and public research organizations (PROs hereafter) to commercialize research through licensing and/or academic spin-offs. This institutional pressure has been inspired by several factors. For example, there was the belief among European policy-makers in a so-called "innovation paradox" emphasizes that Europe leads in producing publications, but lacks commercial skills. Most European universities were facing increasing numbers of students while budgets stayed the same putting enormous pressure on research time and budgets. Together these elements induced the belief that the commercialization of IP through licenses, and spin-offs in particular, could generate a new revenue stream and lead to economic growth in the region. Furthermore, the availability of public funds aimed at addressing the so-called financing and knowledge gap is another element. The financing gap implies that academic spin-offs suffer from an elevated need for finance early in the start-up phase. 
Due to uncertainty, information asymmetries, and transaction costs associated with investing at such an early stage, attracting private venture capitalists may be especially difficult (Lockett et al., 2002; Moray and Clarysse, 2005). Consequently, governments have tried to address this gap through a variety of public policy instruments. With so many facilitators, it is no surprise that academic spin-off activity has been increasing in Europe. Although researchers tend to converge on the factors that lead to an increase in the number of start-ups, much less is known about the impact of these on the quality of the spin-offs created (Lockett and Wright, 2005). The quality of the spin-offs can be accessed through the resources these companies are able to acquire at start-up and their shortterm performance after start-up (Clarysse et al., 2007). This paper analyze this research gap by investigating the most used indicators to evaluate the short-term and long-term result of the technology transfer throw the creation of academic spin-offs.

\section{Spin-offs evaluation indicators used in literature}

\subsection{Growth indicators}

In the last decade several scholars have addressed the issue on the assessment of the academic spin-offs performance using sometimes the same growth indicators and sometimes different. This chapter compares the different growth indicators mostly used in these years. In 2005Davidsson et al. in their paper assessed the suitability of the growth indicators to evaluate the spin-off performance.

"While sales may be the most universally applicable growth indicator it is not always the best one. As Penrose (1959: 199) stated almost half a century ago, "there is no way of measuring an amount of expansion, or even the size of a firm, that is not open to serious conceptual objections." For example, high tech companies with rather long development times, such as biotech companies, are not able to display any growth in sales or revenues for long periods of time. Yet, during this period they might still grow in terms of assets-including knowledge assets such as patents - and employment."

In 2008 Zhang used the venture capital data to evaluate the performance of university spin-offs.

"After controlling for industry and other relevant factors, university spin-offs have a higher survival rate but exhibit no significant difference from other venture-backed firms in terms of the amount of VC money raised per round, total amount of VC raised, the possibility of completing an IPO, the probability of making a profit, or employment size. There are several possible reasons why university spin-offs tend to survive longer. It may be that the higher opportunity cost of academic entrepreneurs motivates them to engage in more self-screening before they create a company. It is also possible that university spin-offs are built around a truly advanced technology that enhances the company's chance of survival."

Zhou in 2010 discussing case studies "attempts to describe two critical cases in order to advance the preliminary framework" used, as growth indicators in the graphs, the revenue growth and the employment growth. In the same year Salvador to measure the performance of the spin-offs (and start-ups) used sales.

"I employed sales, which is the growth measure suggested in entrepreneurship

literature (Covin, Slevin, 1991 ; Lumpkin, Dess, 1996). This measure may be

considered as a relevant one, providing reliable and consistent results

(Chandler, Hanks, 1993).

In 2011 Wennberg et al. analysed the performance differences between university spinoffs and corporate spinoffs starting from this one research question: "Firms started by university-educated entrepreneurs as commercial spinoffs perform better than firms started by university-educated entrepreneurs as university spinoffs in terms of [a] growth in sales revenue, [b] growth in employment, and [c] survivability."

In 2014Agostini et al. to test if protecting intellectual property enhance firm economic and financial performance used ROA and average sales growth. "In this study, firm economic and financial performance is measured by ROA and average sales growth (SALES_GR). ROA has been largely used in innovation studies (Krasnikov et al, 2009; Artz et al, 2010) and it shows the capacity of a firm to generate profits from its assets. Average sales growth (over a 3-year period) has also been used in past studies (Ernst, 1995; Artz et al, 2010) to assess the impact of innovation activities on firm's growth."

In the same year also Novotny in his paper, focused on motivation and success of academic spin-offs with evidence from Hungary, considers the following indicators. "The study of entrepreneurial motivation is important concerning both spin-off creation and success. 
In academic context entrepreneurial success can be approached by three different ways at least. First, in technology transfer terms (e.g. delivered technologies, economic impact) (Choi and Lee, 2000), second, by market indicators such as revenue, profit, number of employees and firm age (Helm and Mauroner, 2007) and third, in a subjective way, i.e. based on personal feelings."

In 2016 Galati et al. tested causal connections, in terms of both type (negative or positive) and intensity, between growth performance indicators and obstacles (that it will show in the next paragraph). The growth indicators used by the authors in this paper are: growth in sales, employment growth and growth in markets number. The identification of growth indicators most commonly used by the researchers is not sufficient to provide an objective evaluation of the performance of academic spin-offs. A long list of internal and extern a factors have been hypothesized and shown to influence firm growth. It is probably the case that every theoretically reasonable suggestion for a growth determinant has been shown to have the predicted impact in some context. The problem is to develop better knowledge about the relative and combined effects of the many predictors under different circumstances. In order to deal with this complexity researchers have developed a set of useful strategies. One is to increase the level of abstraction and regard the many particularities as aspects of more over-riding factors, some of which influence growth directly while others only have an indirect impact. (Davidson et al., 2005)

\subsection{External environment role}

Besides indicating growth indicators most appropriate to the evaluation, Davenport et al. in 2002 assume that "Science parks and cooperative centres associated with universities are examples used internationally of incubator environments designed to nurture spin-offs"

Davidsson et al. also reminded, in the same paper, deterrents and facilitators for growth of the spin-offs.

"Davidsson and Henrekson (2002) hold that the consistency of the theoretical arguments and empirical data makes a strong case for the notion that certain institutions have systematically discriminated against the growth of independent businesses. The specific institutions they investigated included, e.g., regulation of certain sectors of the economy; taxation; wage-setting institutions, and labour market legislation. Carlsson (2002) employs a broader perspective on institutions in his comparison of technology clusters in Sweden and Ohio. The factors he investigates include the science base, mechanisms for technology transfer, density of networks, and what he calls 'entrepreneurial climate'. Again, the conclusion is that Swedish institutions have hampered firm growth."

Also Zhang in his paper identified facilitators for the growth of spinoffs. "...incubatory and other support from parent universities or local governments may have also helped keep university spinoffs in business."

In 2011Fini et al. structured a research model where the dependent variable is the number (count) of academic spin-offs from a given university in a given year and they identified three sets of independent, time-variant variables as predictors of university spin-off activity. The first set, which they labeled university-level control variables (university size, university entrepreneurial eminence, university patenting activity, university research eminence). Second, they addressed University-level support mechanism by gathering information on university incentive structures for faculty to engage in external commercialization activities (university external engagement regulation, university support for technology transfer activities). The third set of independent variables refers to the local-context support mechanisms (regional social capital, regional financial development, regional normative support to entrepreneurship, regional infrastructural support to entrepreneurship, regional knowledge spillovers and regional innovative performance.

In the Meoli and Vismara (2016) model the main explanatory variable, in their analysis of spin-off creation, is the level of administrative support offered by the non-academic staff in a university, including both administrative and technical staff. Therefore they identify two sets of control variables as predictors of spin-off activity. These variables account for the features of the university-specific (size, age, faculty/students ratio, number of academics in science, technology, engineering, and mathematics to the total number of professors, publications per faculty, University patenting activity, technology transfer office size; private university - dummy variable) and the local context (regional GDP growth, regional patenting activity, number of graduates in science, technology, engineering, and mathematics between 20 and 29 years old, R\&D expenditure).

Soetanto and Jack in 2016, instead, using a sample of spin-offs from the United Kingdom, the Netherlands and Norway, analyzed the potential moderating effect of incubation support (networking and entrepreneurial support) on innovation strategy effectiveness. Galati et al. in 2016, as already mentioned, tested the casual connections between growth performance indicators and obstacles. 
They identified 16 obstacles, classified as spin-off-related obstacles (human resources, technical resources, investment capital resources, narrow range of competencies, industrialization, technological forecasting, newness and tacitness, distance from university, location),entrepreneurial team-related obstacles (cultural issues, emotional involvement, networking, academic stasis), university-related obstacles (research level) and government-related obstacles (regulation and bureaucracy). Therefore in order to make a correct assessment of the academic spin-offs performance, it could be appropriate to cross the growth indicators with external factors facilitating and hindering.

\section{Synthesis report and concluding remarks}

This chapter crosses the information about the growth indicators mostly used in literature to evaluate academic spin-offs performances and the external factors that influence more that performances. The next tables below show the results of the cited literature. As shown Table 1 the most widely used growth indicator, in the cited papers, is Sales (8 of 9), following there is Employment (7 of 9), Assets/ROA, profit and survivability/firm age used 2 of 9 times. Finally, used in only one of the papers cited, there is market number. It seems clear that 'Sales' and 'Employment' being most mentioned, by the authors, could represent good indicators to evaluate the spin-offs growth. Instead, as regards the role External environment, the most influencer external factor, as shown Table 2, is the regional and local context with 4 of 7 citations. Incubator/ Science park/ Accelerator and University level, 3 citations of 7, are the second most cited external factors followed by Networks, Technology transfer office and Incubatory ( 2 of 7 ). Finally with a single quote: taxation, regulation, labour market legislation, parent university support and administrative personal support. By this literature review emerged that the growth indicators more suitable for assessing the academic spin-offs appear to be 'Sales' and Employment' and they are strongly influenced by the 'Regional/local context', "Incubator/ Science park/ Accelerator" and 'University level'.

Table 1. Growth indicators synthesis matrix

\begin{tabular}{|l|l|l|l|l|l|l|}
\hline Author/s \& Yr. & Sales & Employment & Assets/ROA & Profit & $\begin{array}{l}\text { Survivability/ Firm } \\
\text { age }\end{array}$ & $\begin{array}{l}\text { Market } \\
\text { number }\end{array}$ \\
\hline Davidsson et al. (2005) & $\mathrm{X}$ & $\mathrm{X}$ & $\mathrm{X}$ & & & \\
\hline Zhang (2008) & & $\mathrm{X}$ & & $\mathrm{X}$ & & \\
\hline Zhou et al. (2010) & $\mathrm{X}$ & $\mathrm{X}$ & & & & \\
\hline Salvador (2010) & $\mathrm{X}$ & & & & & \\
\hline Wennberg et al. (2011) & $\mathrm{X}$ & $\mathrm{X}$ & & & $\mathrm{X}$ & \\
\hline Criaco et al. (2014) & $\mathrm{X}$ & $\mathrm{X}$ & & & & \\
\hline Agostini et al. (2014) & $\mathrm{X}$ & & $\mathrm{X}$ & & & \\
\hline Novotny (2014) & $\mathrm{X}$ & $\mathrm{X}$ & & $\mathrm{X}$ & $\mathrm{X}$ & \\
\hline Galati et al. (2016) & $\mathrm{X}$ & $\mathrm{X}$ & & & & $\mathrm{X}$ \\
\hline Total & 8 & 7 & 2 & 2 & 2 & 1 \\
\hline
\end{tabular}

Table 2. External environment role synthesis matrix

\begin{tabular}{|c|c|c|c|c|c|c|c|c|c|c|}
\hline $\begin{array}{l}\text { Author/s \& } \\
\text { Yr. }\end{array}$ & Taxation & Regulation & $\begin{array}{l}\text { Labour } \\
\text { market } \\
\text { legislation }\end{array}$ & Networks & TTO & $\begin{array}{l}\text { Incubator/ } \\
\text { Science } \\
\text { park/ } \\
\text { Accelerator }\end{array}$ & $\begin{array}{l}\text { Parent } \\
\text { University } \\
\text { support }\end{array}$ & $\begin{array}{l}\text { Regional/ } \\
\text { Local } \\
\text { context }\end{array}$ & $\begin{array}{l}\text { Administrative } \\
\text { Personal } \\
\text { support }\end{array}$ & $\begin{array}{l}\text { University } \\
\text { level }\end{array}$ \\
\hline $\begin{array}{l}\text { Davenport } \\
\text { et al. } \\
(\mathbf{2 0 0 2})\end{array}$ & & & & & & $\mathbf{X}$ & $\mathbf{X}$ & & & \\
\hline $\begin{array}{l}\text { Davidsson } \\
\text { et al. } \\
(\mathbf{2 0 0 5})\end{array}$ & $\mathbf{x}$ & $\mathbf{x}$ & $\mathbf{x}$ & $\mathbf{x}$ & $\mathbf{X}$ & & & & & \\
\hline $\begin{array}{l}\text { Zhang } \\
\text { (2008) }\end{array}$ & & & & & & $\mathbf{x}$ & $\mathbf{x}$ & $\mathbf{x}$ & & \\
\hline $\begin{array}{l}\text { Fini et al. } \\
\text { (2011) }\end{array}$ & & & & & $\mathbf{X}$ & & & $\mathbf{x}$ & & $\mathbf{x}$ \\
\hline $\begin{array}{l}\text { Meoli and } \\
\text { Vismara } \\
\text { (2016) }\end{array}$ & & & & & & & & $\mathbf{x}$ & $\mathbf{x}$ & $\mathbf{x}$ \\
\hline $\begin{array}{l}\text { Soetanto } \\
\text { and Jack } \\
\text { (2016) }\end{array}$ & & & & $\mathbf{x}$ & & $\mathbf{X}$ & & & & \\
\hline $\begin{array}{l}\text { Galati et } \\
\text { al. (2016) }\end{array}$ & & & & & & & & $\mathbf{X}$ & & $\mathbf{X}$ \\
\hline Total & 1 & 1 & 1 & 2 & 2 & 3 & 1 & 4 & 1 & 3 \\
\hline
\end{tabular}




\section{Bibliography}

Abel, Jaison R., and Richard Deitz (2012), "The Role of Colleges and Universities in Building Local Human Capital" Current Issues in Economics and Finance 17(6): 1-7.

Agostini, L., Filippini, R., \& Nosella, A. (2014). Protecting intellectual property to enhance firm performance: does it work for SMEs\&quest. Knowledge Management Research \& Practice.

Clarysse, B., Wright, M., Lockett, A., Mustar, P., Knockhaert, M., (2007) "Academic spin-offs, formal technology transfer and capital raising". Industrial \& Corporate Change. Aug2007, Vol. 16 Issue 4, p609-640. 32p.

Criaco, G., T. Minola, C. Serarols-Tarres, A. Yash Bhatiya (2013). Companies Spun Out of Universities: Different Typologies for Different Performance Patterns. Handbook of Research on Techno-Entrepreneurship, Vol. 2.

Davidsson, P., Achtenhagen, L., \& Naldi, L. (2005). Research on small firm growth: a review.

Etzkowitz, H. (2003): Research groups as 'quasifirms':The invention ofthe entrepreneurial university, Research Policy, 32, pp. 109-121.

Etzkowitz, H., Webster, A., Gebhardt, C. and Terra, B.R.C. (2000): The future of the university and the university of the future: Evolution of the ivory tower to entrepreneurial paradigm, Research Policy, 29, pp. 313-330.

Festel G., Rittershaus P., (2014). Journal of Commercial Biotechnology. Vol. 20 Issue 2, p5-10.

Festel, G. (2015) Technology transfer models based on academic spin-offs within the industrial biotechnology sector. International Journal of Innovation Management, Vol. 19 Issue 4, p-1. 34p. 3

Fini, R., Grimaldi, R., Santoni, S., \& Sobrero, M. (2011). Complements or substitutes? The role of universities an local context in supporting the creation of academic spinoffs. Research Policy, 40(8), 1113-1127.

Galati, F., Bigliardi, B., Petroni, A., Marolla, G. (2016). Which factors are perceived as obstacles for the growth of Italian academic spin-offs?. Technology Analysis \& Strategic Management, Vol. 29 Issue 1, p84-104. 21p.

Lockett, A., G. Murray and M. Wright (2002), 'Do UK venture capitalists still have a bias against high tech investments?,' Research Policy, 31, 1009-1030.

Meoli, M., Vismara, S. (2016) University support and the creation of technology and non-technology academic spinoffs. Small Business Economics, Vol. 47 Issue 2, p345-362. 18p. 6

Moray, N. and B. Clarysse (2005), 'Institutional change and resource endowments to sciencebased entrepreneurial firms,' Research Policy, 34(7), 1010-1027.

Naito, Atsushi (2013), "Instability and Unsustainability of Cognitive Capitalism: Reconsideration from a PostKeynesian Perspective," Knowledge Cultures 1(4): 47-66.

Nica E., Popescu G.H. (2014), "The economics of higher education in the United States" Knowledge Horizons Economics - Volume 6, No. 1, pp. 87-90 (ISSN: 2069-0932, E-ISSN: 2066-1061)

Novotny, A. (2014), Motivation and Success of Academic Spin-Offs; Evidence from Hungary, The Annals of the University of Oradea, Vol. XXIII, pp. 1212-1219.

OECD (2003), Turning Science into Business, Patenting and Licensing at Public Research Organisations. OECD: Paris

Quetglas, G.M., Grau, B. G. (2002). Aspects of University Research and Technology Transfer to Private Industry. Journal of Business Ethics, Volume 39, Issue 1, pp 51-58

Roberts EB (2007). "Managing invention and innovation". Research-Technology Management, 50(1), 35-54.

Rodríguez-Gulías, M., Fernández-López, S.; Rodeiro-Pazos, D. (2016). Growth determinants in entrepreneurship: A longitudinal study of Spanish technology-based university spin-offs. Journal of International EntrepreneurshipVol. 14 Issue 3, p323-344. 22p.

Salvador, E, (2010). How effective are research spin-off firms in Italy? Rev ÉconInd, 99-122

Siegel, D. S., D. Waldman and A. N. Link (2003), Assessing the impact of organizational practices on the relative productivity of university technology transfer offices: an exploratory study, Research Policy, 27-48.

Soetanto, D., Jack, S.. (2016) The impact of university-based incubation support on the innovation strategy of academic spin-offs. Technovation, Vol. 50/51, p25-40. 16p.

Vaiva, P. (2016). Does the global competitiveness index demonstrate the resilience of countries to economic crises?. Ekonomika / Economics, Vol. 95 Issue 3, p28-36. 9p.

Wennberg, K., Wiklund, J., \& Wright, M. (2011). The effectiveness of university knowledge spillovers: Performance differences between university spinoffs and corporate spinoffs. Research Policy, Vol 40, No. 8, pp 1128-1143.

Zhang, J. (2009). The performance of university spin-offs: an exploratory analysis using venture capital data. The Journal of Technology Transfer, Vol 34, No. 3, pp 255-285.

Zhou, Y., T. Minshall, et al. (2010). Building Innovation Capabilities: An Inquiry into the Dynamic Growth Process of University Spin-outs in China. Int. J. Innovation and Technology Management 7 (Nos. 3): 273 - 302. 